\title{
Subjective Probabilities: Psychological Theories and Economic Applications
}

\author{
Abbigail J. Chiodo, Massimo Guidolin, Michael T. Owyang, and Makoto Shimoji
}

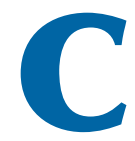
onventional economic analysis of individual behavior begins with the assumption that consumers maximize expected utility, optimizing their planning for the future. Economists incorporate this assumption in models by endowing consumers in those models with the skills of a good statistician - that is, the ability to make rational (and often complicated) calculations. While not always realistic (perhaps never), this assumption facilitates the use of economic models that may work well in the real world. However, in some cases, these models cannot explain some of the evidence uncovered in psychological experiments. In other words, the traditional statistics-based approach sometimes fails to predict individual behavior and aggregate market outcomes that are consistent with the empirical evidence. For instance, observed stock prices and portfolio choices fail to conform to the implications of well-known frameworks, such as the capital asset pricing model (CAPM). Such cases have encouraged a branch of economics that borrows ideas from psychology to explain these discrepancies. ${ }^{1}$

In this area of study, researchers replace the assumption that individuals use complicated statistical formulas to maximize expected utility with the likelihood that they use simple rules of thumb instead, rules that have been identified by psychological research. Psychologists have found evidence that individuals estimate the probability of future outcomes in a nonstatistical, or subjective, manner. Kahneman and Tversky (1973) and Kahneman, Slovic, and Tversky (1982), among others, have introduced the idea of subjective probability heuristicsrules that people tend to rely on when assessing the likelihood of alternative events. Psychological

1 This vein of research is, in some part, attributed to the cross-disciplinary work of Amos Tversky and 2002 Nobel laureate Daniel Kahneman. research has shown that the use of these rules can create different outcomes from what statisticians (and economists) might expect, both in the estimated probabilities and in observed behavioral patterns.

Behavioral theories of decisionmaking therefore ask whether economic phenomena may be explained by models in which

- Some, but not necessarily all, agents either fail to update their probabilistic beliefs by applying the appropriate statistical rules or subsequently fail to maximize a standard expected utility objective.

- The remaining fully rational agents, then, cannot completely exploit and eliminate the biases caused by the actions of agents who are not perfectly rational.

While these heuristics are drawn from psychological studies, they may be supported by economic models with boundedly rational agents (Simon, 1955). In other words, agents do not always have the time or the cognitive ability to process all of the data provided by the economic environment with the necessary accuracy. Instead, people might employ these heuristics to arrive at analyses that are less costly to calculate than optimal decisions (Evans and Ramey, 1992); and, often, the optimal decisions themselves are impossible to calculate for difficult problems. Thus, boundedly rational agents do not maximize expected utility as an economist would generally assume. Instead, they maximize perceived expected utility, a quantity based not on actual probabilities but on their beliefs about those probabilities (Rabin, 1998, 2002).

In this article, we focus on the nature and application of psychological rules for probability formation and the biases from anticipated economic

Abbigail J. Chiodo was a research associate at the Federal Reserve Bank of St. Louis while this article was written. Massimo Guidolin is an assistant professor of economics at the University of Virginia. Michael T. Owyang is an economist at the Federal Reserve Bank of St. Louis. Makoto Shimoji is an associate professor, International Graduate School of Social Sciences, Yokohama National University. Kristie M. Engemann and Mark L. Opitz provided research assistance.

Federal Reserve Bank of St. Louis Review, January/February 2004, 86(1), pp. 33-47.

(1) 2004, The Federal Reserve Bank of St. Louis. 
outcomes that can result from their use. ${ }^{2}$ We examine three heuristics that have been identified by psychologists: the representativeness heuristic (RH), the availability heuristic $(\mathrm{AH})$, and anchoring and adjustment (AA). We review the psychological evidence supporting the common use of these heuristics in estimating subjective probabilities. Finally, we consider a financial application that uses heuristics to estimate probabilities with potentially important economic implications. We then show the effect of these heuristics on people's probability judgments.

\section{PSYCHOLOGICAL EVIDENCE}

Economics has a long history of exploring human behavior in decisionmaking. Economic models often require agents to form expectations under uncertainty, e.g., expected inflation in macroeconomic models, expected returns in financial models, or expected utility in decision/choice models. However, when faced with calculating expectations, economists often assume that the probabilities are known or can be inferred (rationally) through learning. What is meant by this? An economic agent might maximize his expected utility over $n$ uncertain outcomes, defined as

$$
E U=\sum_{i=1}^{n} p_{i} U_{i}
$$

where $p_{i}$ is the probability of outcome $i$ and $U_{i}$ is the utility from outcome $i$.

Psychologists, however, have found that people neglect some available information in their decisionmaking process - that is, they do not update probabilities as new information arrives, as an agent adhering to rational expectations would. Consistent with Rabin's idea of perceived expected utility, agents might maximize

$$
E U^{p}=\sum_{i=1}^{n} \hat{p}_{i} U_{i}
$$

where $\hat{p}_{i}$ is the subjective probability of outcome $i$. The difference between equations (1) and (2) is solely in the agent's assessment of the likelihood that $i$ will be realized. In this section, we explore how economists and psychologists view $p_{i}$ and $\hat{p}_{i}$ differently.

\footnotetext{
2 Sherman and Corty (1984) and Camerer (1995) provide surveys of the psychological evidence on the heuristics discussed here. Another strand of the recent behavioral literature focuses on the effects of nonexpected utility preferences for optimal decisions. We do not discuss these contributions and concentrate instead on the process of belief formation.
}

\section{Representativeness}

Tversky and Kahneman (1974) suggest that people typically rely on the representativeness heuristic $(\mathrm{RH})$ when answering "probabilistic questions" such as "What is the probability that event A originates from process $B$ ?" That is, the RH is used when a person must determine such probabilities based on the degree to which A resembles B.

$\mathrm{RH}$ is used when an agent must update a subjective probability with new information. Economists sometimes assume that agents employ Bayes's law when updating probabilities. Bayes's law defines the probability of an event $X$, conditional on observing $A$, as

$$
p(X \mid A)=\frac{p(A \mid X) p(X)}{p(A)},
$$

where $p(A \mid X)$ is the conditional probability of $A$ given $X$ and $p(X)$ and $p(A)$ are population parameters typically referred to as base rates.

While Bayes's law is a useful statistical rule, psychologists have found that people tend to act in a decidedly non-Bayesian fashion and have identified a number of subjective probability biases grouped under the umbrella of $\mathrm{RH}$.

Tversky and Kahneman (1974) and Kahneman, Slovic, and Tversky (1982) note that using RH when determining probability can lead to insensitivity to prior probability, or base-rate frequency, of the outcomes. ${ }^{3}$ In one example, subjects were asked to identify a described individual as either a lawyer or an engineer. The subjects were given descriptions that included phrases such as "he wears glasses" or "he wears a pocket protector." Subjects were first told that the individual in question was drawn from a random sample composed of 100 people, 70 of which were engineers and 30 of which were lawyers. Then, the base rates were reversed. The subjects were told that, of the 100 people in the sample, 70 were lawyers and 30 were engineers. Kahneman, Slovic, and Tversky found that the subjects' probability judgments did not differ when the base rate was changed, even though Bayes's law indicates that the conditional probabilities cannot be equal if the base rates change.

Grether $(1980,1992)$ and El-Gamal and Grether (1995) designed experiments that determine that $\mathrm{RH}$ "is a good descriptive model of behavior under

\footnotetext{
3 Sherman and Corty (1984) provide a comprehensive review of the biases that are attributed to $\mathrm{RH}$.
} 
uncertainty for untutored and unmotivated (or at least not financially motivated) individuals" (Grether, 1980 , p. 538). Specifically, they show that subjects under-use base rate information when making subjective probability judgments for events that have little or no consequence or cost. Borgida and Brekke (1981) have also shown that, while most people do not neglect base rates entirely, they are typically under-used.

\section{Availability}

The availability heuristic (AH) describes a method by which a person determines the likelihood of an event according to the ease with which he or she can recall instances that match the event. That is, one's experiences and conditioning affect how a person determines the likelihood that an event will occur. For example, one might estimate the risk of a burglary in a certain neighborhood by the number of burglaries one can recall (including any personal experience).

A similar method is the simulation heuristic, by which people will determine the likelihood of events based on the ease with which they can simulate (or imagine) the outcome in their minds. An example of this is a person who determines the probability that the value of a certain stock will decline based on the number of different scenarios he or she can easily imagine that would cause such an occurrence.

While AH can often be helpful in making decisions and estimates, Tversky and Kahneman (1974) list several biases that can result from $\mathrm{AH}$. These include biases (i) due to the retrievability of instances (examples easily brought to mind are often judged to be more likely than they actually are), (ii) due to imaginability (easily imagined outcomes can give the illusion that they are more common), and (iii) due to illusory correlation (one event more strongly implies another if the two events frequently occur simultaneously).

Tversky and Kahneman (1973) outline several studies used to demonstrate the $\mathrm{AH}$ and its subsequent biases. For example, subjects were read lists of names of both sexes, some of which were names of very famous people (Richard Nixon and Elizabeth Taylor, for example). Afterward, some were asked to estimate if there were more males or females on the list. People tended to estimate, sometimes incorrectly, that there were more of whichever sex had more famous people in the list. The famous names were easier to remember and therefore more prominent in the minds of the subjects. Tversky and Kahneman conclude, then, that people make estimates based on AH, which (in this case) led to the retrievability bias.

AH has been applied to marketing and advertising to investigate the effect of retrieval on the subjective assessment of product failure. Folkes (1988) presents four studies in which subjects were asked to predict how likely various products were to fail. Different scenarios and distinctive brand names were used to make some products or instances more memorable. Folkes found that these judgments were biased in ways described by the $\mathrm{AH}$ - that more memorable products (memorable for various reasons) influenced the subjects' decisions. Rabin (1998) points out that people often give too much weight to memorable evidence, even when better sources of information are available. He notes that one may allow a dramatic personal story from a friend regarding an instance of product failure to be more influential than consumer reports with general statistics regarding that product.

Recently, Mullainathan (2002) developed a model of memory limitations based on two psychological concepts that can have properties similar to $\mathrm{AH}$.

The first concept, rehearsal, is the assumption that remembering an event, story, or some form of information one time makes it easier to remember again. Mullainathan points out that rehearsal is used by students who study for a test by reading over the material and then quizzing themselves to help them remember it. The second concept, associativeness, is the process by which current events can trigger memories of past events that have similar aspects. Thus, even uninformative information-information that does not change the likelihood of an eventcan influence beliefs by changing perceptions of the past. Mullainathan suggests that people respond "too much" because news resurrects memories that reinforce beliefs. ${ }^{4}$

\section{Anchoring and Adjustment}

The final heuristic we address is anchoring and adjustment (AA), which Tversky and Kahneman (1974) define. According to this heuristic, individuals make estimates based on a starting point (the anchor) and update (adjust) their subjective probability based on new information. While this does not seem to differ from RH or even from Bayesian updating,

\footnotetext{
4 Mullainathan considers an application of this model to individuals' consumption decisions. He suggests that individuals react more to their private information than to aggregate information because aggregate information is forgotten.
} 
psychologists have shown that individuals have a propensity to bias their estimated probabilities toward the anchor. That is, individuals do not adjust enough to new information, making the value of the anchor more critical.

An individual's initial guess (the anchor) can be subjective (interpreted) or objective (e.g., taken from base rates). Often, the anchor depends on the manner in which the question is asked or how the information is given. For example, Tversky and Kahneman (1974) asked subjects to estimate the percentage of African countries in the United Nations by first giving them a number (determined randomly by spinning a wheel) and then asking the subjects whether that number was higher or lower than the percentage of African countries. Different initial values led to strikingly different estimates. While the median estimate was 25 percent for groups that received 10 as the starting value, the median estimate was 45 percent for those given a starting value of 65 -illustrating the bias toward the anchor.

A starting value can also be the result of a subject's (usually incomplete) computation. Tversky and Kahneman (1974) give the example of two groups being asked to estimate 8 ! in a limited amount of time. While one group was given $1 * 2 * 3 * 4 * 5^{*} 6 * 7 * 8$ as the problem, the other group was given $8^{*} 7^{*} 6^{*} 5^{*} 4^{*} 3^{*} 2 * 1$. Note that the product of the first few steps of multiplication (performed left to right) of the descending sequence is much higher than that of the ascending sequence. As predicted, the median estimate of the group shown the descending sequence was much higher than the median estimate of the group shown the ascending sequence.

This example illustrates how subjects tend to focus on only part of a problem. For instance, the probability of success at any one stage of an event is often used as a starting point (an anchor) to determine the probability of overall success. However, their assessment of the probability for an event with multiple stages is often skewed because they do not deviate enough from that anchor. Tversky and Kahneman (1974) refer to research that shows how anchoring biases the estimation of probability for different types of events-specifically, that subjects overestimate conjunctive events and underestimate disjunctive events. For example, suppose there is a bag of marbles, half of which are red and half of which are black: People will overestimate the probability of, for instance, drawing a red marble from the bag seven times in succession after replacing the drawn marble (a conjunctive event); they will underestimate the probability of drawing a red marble from the bag at least once in seven successive tries after replacing the drawn marble (a disjunctive event). The anchor for both events is the probability of drawing a red marble on any try. Success in a conjunctive event may be likely for only one of several required outcomes, yet subjects stick close to their anchor and thus overestimate the probability of overall success. Conversely, subjects tend to underestimate the likelihood of success beyond the anchor when multiple attempts are allowed to achieve merely one successful outcome.

\section{ILLUSTRATIVE APPLICATIONS}

To demonstrate the effect of heuristic biases on probability judgments, we offer the following illustrations.

\section{Disaster Insurance}

The biases resulting from these heuristics have some implications in the earthquake insurance market. A large earthquake in one area certainly qualifies as the kind of salient event mentioned in the discussion of the AH. After all, graphic pictures and information from the media or personal stories from friends affected by the earthquake are likely to be easily remembered when estimating one's own need for earthquake insurance. Psychology theory implies, then, that a large earthquake should cause people to overestimate the probability that they will need earthquake insurance, which could explain the "gains by losses" phenomenon: In the event of an earthquake, an insurance company must pay out on claims, incurring a loss; if an earthquake causes an increase in demand for insurance, however, insurance companies can benefit, overall, by experiencing significant gains during the period after the earthquake.

Consider an actuarially fair earthquake insurance policy with premium $\pi$ and payout $Y$. By definition, the actuarially fair premium must be a function of the payout and the risk of the event being insured against. In this case, the premium should exactly offset the expected payouts.

Suppose now that, given the premium, a person must decide whether to purchase insurance based on the perceived likelihood of a loss. Irrelevant information, such as an earthquake in another part of the country, does not affect the probability of a loss. However, a person employing heuristics might assume a greater likelihood of a local earthquake- 
making the insurance contract more attractive to her. Thus, if persons employed the heuristics, we would expect demand for insurance to rise after the occurrence of a similar event.

In fact, Kunreuther et al. (1978) finds that people tend to discount the likelihood of a disaster (e.g., a flood or an earthquake) until the event occurs. After people "update" their assessment, purchases of insurance contracts rise. Moreover, Shelor, Anderson, and Cross (1992) and Aiuppa, Carney, and Krueger (1993) found that insurers' stock prices increased after the 1989 earthquake in San Francisco, due to an increased demand for coverage. However, Yamori and Kobayashi (2002) find no such benefit to insurance companies in Japan after the 1995 HanshinAwaji earthquake. Yamori and Kobayashi note that unique attributes of Japanese earthquake insurance may be the reason for the difference between the United States and Japan in stock market reactions to large earthquakes. Namely, the Japanese government sets the insurance industry premium levels at "no loss and no profit." Interestingly, while studies have shown the positive link between earthquakes and insurance stock prices in the United States, other studies indicate no such relationship for hurricanes. ${ }^{5}$

\section{Product Liability}

A second application for the heuristics involves market attitude with regard to product reputation, specifically, shocks to reputation. We can model market behavior after a product failure as a temporary shift in demand that results in lower sales and falling retail and stock prices.

Airplane Crashes. News agencies report airplane crashes in detail, often exhaustively and over an extended period of time. These reports provide vivid images to the public. ${ }^{6,7}$ As a consequence, people may avoid air travel, at least for some amount of time. Without an $\mathrm{AH}$, such tragedies would have little effect on people's belief regarding air travel safety because these events are rather uncommon and it is widely known that air transportation has been much safer than any type of

\footnotetext{
5 See Lamb (1995) and Cagle (1996) for details.

6 By "airplane crashes," we do not mean the consequence of terrorism or hijacking, which are due to external forces.

7 In the previous case, we argued that some of the events are consistent with the presence of the AH. In this section, we also survey several examples of product detection, e.g., product recalls. Although most of the failures are also life-threatening, like the examples above, there is no evidence of spillover effects in the industry as a whole, unlike the examples above.
}

ground transportation in the United States. Because the change in people's beliefs regarding the overall safety of air travel would be minimal, this type of tragedy would be interpreted as idiosyncratic to a particular airline. In this case, it is therefore possible that other airlines (the rivals of the airline that experienced a crash) would benefit from such an event. If an AH does exist among the potential customers, however, the demand for air travel as a whole would decline. This externality would harm the market as a whole, and, as a consequence, other carriers would lose profits as well.

Borenstein and Zimmerman (1988) found that "an airline's shareholders suffer a statistically significant wealth loss when the airline experiences a serious accident...[although] the average loss in equity value is much smaller than the total social costs of an accident" (p. 913). In addition, they found that (i) such accidents have little or no effect on demand and (ii) that there is little evidence of a externality effect (positive or negative) caused by such accidents on the demand for other airlines. This study suggests that the market barely reacts to these events.

A subsequent study by Mitchell and Maloney (1989) partitioned the sample into "at-fault" crashes (those caused by pilot error) and all other crashes and tested whether these two distinct groups receive different reactions from the market. Contrary to the study by Borenstein and Zimmerman (1988), they found a statistically significant negative reaction in the former group. ${ }^{8}$ However, these studies do not offer an insight regarding the effect of an $\mathrm{AH}$.

Nethercutt and Pruitt (1997) reported a finding similar to that of Mitchell and Maloney (1989) by examining the Valujet accident in 1996. In their study, they found two things: (i) not only the shareholders of Valujet but also those of other "low cost" carriers suffered losses due to this accident and (ii) the shareholders of the major airlines indeed received statistically significant gains after this event. At first sight, this result seems to suggest the nonexistence of an AH. However, their study does not distinguish the switching effect from the spillover effect; hence, it does confirm that the former dominates the latter, but has nothing to say about the effect of an AH.

The study by Bosch, Eckard, and Singal (1998) partially answers the question raised above. The authors consider the market overlaps of airlines in

8 See also Broder (1990). 
the context of a recent airplane crash and examine whether customers respond to a commercial airline crash by switching to rival airlines and/or flying less. They find that passengers who do choose to fly will travel on the airlines that have not had a recent crash, but even these airlines suffer a negative spillovernamely, fewer passengers overall. With market overlap, the coexistence of the switching effect and the spillover effect offset each other and we can observe only the net effect of these two together. However, with little overlap, the switching effect is limited and hence we can test if the spillover effect exists. Indeed, Bosch, Eckard, and Singal found negative spillover effects after airplane crashes, consistent with the existence of the AH.

Firm Bankruptcy. Lang and Stulz (1992) studied the effect of one firm's bankruptcy announcement on the other firms in the same industry. They listed two effects of such an announcement ${ }^{9}$.

Contagion Effect. A change in the value of competitors that cannot be attributed to wealth redistribution from the bankrupt firm. This may happen because investors think that firms with characteristics similar to those of the bankrupt firm are less profitable than expected.

Competitive Effect. A change in the value of competitors that can be attributed to wealth redistribution from the bankrupt firm. This may happen, for example, if investors think that the bankrupt firm is doing poorly because other firms are doing well.

As for the first effect, they found that "on average, the market value of a value-weighted portfolio of the common stock of the bankrupt firm's competitors decreases by $1 \%$ at the time of the bankruptcy announcement and the decline is statistically significant" (p. 46). They also reported that "the effect appears to be greater for highly leveraged industries" (p. 46). For the second effect, they found that "the value of competitors' equity actually increases by $2.2 \%$ in more concentrated industries with low leverage" (p. 47).

These types of effects may be due to other announcements or events such as defective products and recalls. ${ }^{10}$ In addition, even though the same types of effects are observed, they may arise from other sources. In the following, we discuss such

\footnotetext{
9 Note that contagion affects all the relevant firms in the same negative direction, whereas the competitive effect does not

${ }^{10}$ For example, Ford Motor Company experienced a decline in sales after the Firestone tires used on Ford products were declared faulty by the media.
}

possibilities, as well as the possibility that some of the events may be attributed to the existence of heuristics we study in this paper.

\section{A FINANCIAL APPLICATION}

We now consider an application of heuristic probability judgments in an asset pricing model. ${ }^{11}$ A formal description can be found in the appendix. Recently, Barberis and Thaler (2002) have stressed how behavioral approaches that focus on the mechanism of expectation formation cannot be applied to explanations of well-known aggregate puzzles in finance, such as the equity premium, excess volatility, and predictability issues. Although it is acknowledged that many models developed to investigate the crosssection of asset returns may often be used to also explain aggregate puzzles, much remains to be achieved by this strand of literature. ${ }^{12}$ In this section we discuss a number of asset pricing puzzles that can be explained by subjective probability biases. ${ }^{13}$

\section{How Do Subjective Probabilities Affect Asset Prices?}

Assume there are two assets: a single-period, risk-free discount bond in zero net supply and a publicly traded stock (or stock index) in exogenous, unit supply. The stock pays out an infinite stream of perishable, real dividends, the growth rates of which randomly switch between two values: $d_{h}$ in the good state (an expansion) and $d_{l}$ in the bad state (a recession).

Individuals use both informative and uninformative variables to determine probability estimates. For simplicity, assume that the only informative variable is dividends. Dividends are informative because they directly relate to the payouts produced by the stock. Therefore, the information set is com-

\footnotetext{
11 Barberis and Thaler (2002) and Hirshleifer (2001) are recent survey papers on the field of behavioral finance. See Mullainathan (1998) for an application of the AH to finance.

12 Several papers have used nonexpected utility preferences consistent with the psychological and experimental evidence to approach the same phenomena (for instance, Barberis, Huang, and Santos, 2001, and Benartzi and Thaler, 1995). These papers are often considered to belong to the behavioral camp

13 It goes without saying that a vast literature has developed over the past two decades that approaches the same puzzles we discuss; these have used types of frictions (transaction costs, information asymmetries and incomplete information, nonstandard preferences, etc.) that do not involve either the process of expectation formation or the ability of investors to rationally use the available information. The surveys in Campbell (2000) and Cochrane (2001) offer highly readable accounts and references.
} 
posed of the sequence of realized high and low dividend growth rates plus a set that collects all the relevant realizations of the uninformative variables. Examples of uninformative variables are past stock prices because stock prices fail to add any predictive power for future cash flows produced by the stock currently owned. Alternatively, investors might use past levels of the price-dividend ratio to forecast future dividend growth because this ratio has been found to successfully predict stock prices in the empirical literature. In practice, stock market participants will directly care about the probability for dividends only. However, depending on the way subjective probabilities are formed, investors might indirectly also care about the joint probability distribution of dividends and the uninformative variables, in the sense that they might use uninformative events to predict dividends.

\section{The Heuristics-Based Solution}

Suppose that the probability of an increase in dividends is unknown and must be subjectively calculated based on past observations. ${ }^{14} \mathrm{~A}$ representative agent believes that the value of the stock depends not only on past dividend payments but also on the irrelevant information she has in her information set. ${ }^{15}$ Since events that are recent are more likely to be remembered, the further back in time an observation on the dividend growth rate is, the more unlikely it is that it will belong to the recalled information set. However, agents recall events that bear a high resemblance to current events, even when the similarity is defined not only in terms of dividends, but also in terms of other, irrelevant variables (e.g., past asset prices). For instance, an investor is more likely to recall a big drop in a company's dividend when it is associated

\footnotetext{
14 Barsky and DeLong (1993) present a discounted model in which investors form extrapolative expectations and generate excess volatility of stock prices. However, their paper does not impose much structure on belief formation and fails to link the extrapolation process to the experimental psychology literature.

${ }^{15}$ For a heuristic rule to have an effect on equilibrium outcomes, irrational traders need not be completely weeded out of the economic system (through bankruptcy or reduction to a marginal role in determining equilibrium results). Although the debate in the economics literature is not settled yet, important papers in finance (DeLong et al., 1990a,b, 1991) shed light on the subject: namely, that the price biases created by simple heuristics (such as the case with random trading of securities) create situations in which the exploitation of less-rational investors is risky and therefore fails to be implemented on the scale necessary to completely annihilate the effects of the biases (Shleifer and Vishny, 1997). Therefore, heuristics might appear in the aggregate and a representative agent is a useful shortcut to model such a situation.
}

with a deep international crisis, even though the political variables need not carry information useful in predicting future economic conditions or the profitability of the company.

The appendix shows that, under these assumptions, the heuristic-based equilibrium stock price differs from the full-information equilibrium price because it stops being a fixed multiple of dividends; on the contrary, the heuristic-based equilibrium price-dividend ratio now contains a time-varying component, fitting the empirical finding that pricedividend ratios are subject to long swings. The variation in the price-dividend ratio derives from changes in the investors' memory-based (or subjective) expectation of dividends. For instance, particularly bad dividends may depress stock prices to the point that investors start recollecting previous bad times when the observed mean dividend growth was low. This happens because, when the AH is present, low growth tends to make other episodes of low growth salient and to bring up memories of other recessions; this happens also because poor dividend growth depresses stock prices and makes other recessionary episodes more memorable. These biases depress the subjective dividend expectations and cause deeper persistent declines in stock prices.

\section{Excess Volatility of Stock Prices}

We now investigate a few qualitative implications for stock prices. Since Shiller (1981) and LeRoy and Porter (1981), researchers have observed that stock prices tend to be much more volatile than the underlying economic fundamentals (dividends or aggregate consumption) would dictate. Recent research has examined this issue with mixed success (see Brennan and Xia, 2001, Bullard and Duffy, 2001, and Timmermann, 2001). Under full-information rational expectations, this finding represents a puzzle. ${ }^{16}$ The heuristics-based approach illustrates how the excess stock volatility puzzle can be easily resolved when the price-dividend ratio is timevarying as a result of limited memory and of avail-

\footnotetext{
${ }^{16}$ Barberis and Thaler (2002) informally discuss a psychological model that could explain the excess volatility puzzle: Investors perceive a disproportionate volatility of the dividend growth rate when they are exuberant, i.e., when they observe dividend increases that convince them, too quickly, that mean dividend growth has increased. Although Barberis and Thaler notice that a similar story may be derived as an application of the RH, they do not present a formal model that maps heuristics into beliefs. Shiller (2003) has recently used the excess volatility puzzle as a workhorse to introduce behavioral finance research to overcome the traditional efficient market hypothesis.
} 
ability, representativeness, and anchoring biases. The appendix provides a formal treatment.

Since high dividends are generally accompanied by high stock prices and low dividends by low stock prices, a high growth realization will make past high dividend growth rates more memorable because of the $\mathrm{AH}$. This is because, if a high dividend growth rate causes an increase in stock prices, other episodes of bull markets and good fundamentals will be recalled. Such an event is likely to increase the subjective expectation of dividends and the price-dividend ratio. A similar reasoning applies to situations of low fundamentals and stock prices, i.e., they will generally make "bad times" more memorable and depress the expectation of future dividends. Therefore we expect positive covariation between dividend growth and the price-dividend ratio, which makes stock prices much more volatile than what is implied by full-information rational expectations. In this sense, heuristics-based asset pricing makes the solution of the volatility puzzle not only possible, but likely.

\section{Bubbles and Crashes}

A related topic is the tendency of stock mar kets to experience long periods of sustained (but hardly rational) increases in prices, followed by quick outbursts that often lead to sudden crashes. With reference to these phenomena, economists have developed both a literature on the theoretical conditions under which price bubbles may form and thrive (see Tirole, 1985) and a more recent empirical literature that describes markets as going through a sequence of "bulls" and "bears" (see Perez-Quiros and Timmermann, 2000). Unfortunately, the former mostly stresses the delicacy of bubbles, while the latter falls short of providing answers to our questions because it focuses on the microfoundations of bulls and bears. When investors use heuristics, bubbles and crashes occur in equilibrium more frequently.

Suppose the current period is characterized by good economic fundamentals and hence positive stock returns. In particular, some degree of exogenous optimism may easily project good dividend growth in high stock returns. At this point the following mechanism is triggered: A high current stock price elicits memories of previous periods of fast economic growth and "good" fundamentals. When past stock prices are also used to calculate expectations of future dividend growth, high current prices will also make past bull market periods more mem- orable. Hence, past high-dividend periods will be assigned an abnormally high probability and will end up being over-represented in the recalled information set. As a result, expected dividends will be irrationally high. Unless the next-period dividend is particularly unfavorable, this sustains high demand for equities and stock prices: This is the beginning of the bubble. In such an environment it would be possible for stock prices to increase at such a pace that (given agents' imperfect memory), in practice, only very recent bull periods would be recalled and used in forming expectations. Here, it is as if the market enters an entirely different world: Optimism dominates to the point where price increases are a foregone conclusion (c.f., the "New Economy"). ${ }^{17}$

The effect is further enhanced when anchoring is strong: If the run of price increases is sufficiently protracted, agents' subjective perception of the probability of good economic fundamentals will become increasingly difficult to move. ${ }^{18}$ What ends a bubble? Potentially, a sufficiently negative realization of fundamentals growth. Such an epiphany could suddenly make investors recall past cases in which bull markets turned into bear markets. In other cases, it is sufficient that some variables, although irrelevant for pricing (political variables, for instance), may suddenly make investors aware that bad outcomes are possible. When this happens, the bubble bursts, often plunging into a catastrophic crash.

One phenomenon that has not been well explained by the theoretical literature on bubbles is the possibility of protracted periods of depressed stock prices, far below their most moderate rational levels - a sort of negative bubble (Weil, 1990). An advantage of heuristic-based asset pricing is the ability to generate episodes of irrationally low stock prices. Starting with poor underlying growth and some pessimism, markets may quickly plunge into spells in which investors focus only on past negative news and periods and, hence, systematically underestimate the mean dividend growth rate so that stock prices are too low given the quality of the underlying fundamentals. Strong anchoring may complete the picture, thus damping investors' expectations for growth prospects.

\footnotetext{
17 See, for instance, The Economist, "Beyond the Business Cycle?" October 23, 1999, and the "new era" theories discussed in Shiller (2000).

18 Intuitively, anchoring makes bubbles harder to ignite but also harder to burst. Given the available empirical evidence, the behavior of financial markets is highly consistent with strong anchoring.
} 


\section{The Inflation-Stock Returns Puzzle}

It is conventional wisdom to prefer nominal stock returns and inflation to be positively and highly correlated; rational markets, then, should price equities based on their discounted, expected nominal cash flow payments. Therefore, ruling out deeper macroeconomic effects (e.g., sectoral shifts and other distortions), an increase in current and expected inflation ought to increase expected nominal dividend payments and cause upward adjustment of observed stock prices. Empirical research in the past 20 years has found very limited support for the hypothesis that stock returns can protect shareholders from inflation. Normally, positive but moderate correlations have been found. In other words, the Fisher equation systematically fails for nominal stock returns. ${ }^{19}$ Heuristic-based asset pricing offers an easy way to rationalize such a phenomenon.

Suppose that inflation not only influences nominal dividend levels, but also acts as a variable in the set of uninformative information. In particular, assume that investors have convinced themselves that high inflation is always accompanied by subsequent increases in the level of real interest rates that depress economic growth. Interestingly, this conjecture does not need to be supported by the data, or it might be supported only by old data. Inflation is just an additional variable that becomes informative of future economic growth only because investors think it is. In this case, a high current inflation rate is essentially bad news: It makes past periods of poor growth and recession more memorable (via availability) and accelerates inflation (via representativeness). In practice, two effects take place at once: On one hand, inflation raises expected nominal dividends; on the other hand, inflation induces a pessimistic change in the agent's recalled information set, lowering expected real dividends. The net effect is unclear but is consistent with the fact that nominal stock returns do not seem to react much to inflation news. ${ }^{20}$

\footnotetext{
${ }^{19}$ Equivalently, empirical studies have found negative correlation between real stock returns and inflation, both expected and unexpected. See, for instance, Nelson (1976) and Fama and Schwert (1977) for early evidence.

${ }^{20}$ Geske and Roll (1983) propose a theoretical model in which the only exogenous shocks are disturbances to the real level of economic activity. Since they assume monetary policy acts counter-cyclically, the negative correlation between real stock returns and inflation derives from the fact that bad news on fundamentals forecasts higher future monetary growth and inflation. However, the recent debate
}

\section{CONCLUSION}

In this article, we surveyed some of the research that has highlighted the crossover between economics and psychology. The assumptions economists have traditionally imposed in their models maintain that individuals are rational (and selfish) and construct their beliefs according to probability theory, following Bayes's law. For most economic applications, this type of assumption fits well. However, there remain situations in which nonrational or quasirational behavior on the part of the median agent is observed. In these situations (e.g., hazard insurance and asset pricing), assuming that people behave rationally leads to puzzles - such as the inflation-stock returns puzzle, bubbles and crashes, and excess stock price volatility - that are yet unexplained using standard economic theories.

Economists have more recently begun to acknowledge irrationality as a source of interest for these economic applications. Accounting for all idiosyncratic effects is literally impossible and, moreover, undesirable. Economic theory adequately explains many types of behavior, including consumption behavior, for example. However, there remain some systematic deviations from rational behavior, which the standard models do not fully capture. The heuristics that psychologists suggest are examples of this. Incorporating these types of behavioral rules in our research could not only broaden how we approach and analyze subjects but also may greatly increase the power of our conclusions. We find, for example, that the puzzles in the asset pricing literature (such as those listed above) can be accounted for by adding a heuristic probability rule to the standard asset pricing framework. Thus, while behavior might not be a solution that is broadly cast, we propose that its importance, in some circumstances, may warrant further investigation.

\section{REFERENCES}

Aiuppa, Thomas A.; Carney, Robert J. and Krueger, Thomas M. “An Examination of Insurance Stock Prices

over monetary policy reaction functions (see Clarida, Gali, and Gertler, 1999) make a belief-based mechanism more appealing. Marshall (1992) and Bakshi and Chen (1996) offer rational expectations models that generate plausible predictions for the inflation-stock returns relationship. McDevitt (1989) focuses on a nominal tax explanation: In countries with nominal tax components to their tax systems, inflation increases the effective tax rate; an imperfect correlation between stock returns and inflation could then obtain. With the use of an international data set, McDevitt finds little empirical support for the nominal tax approach. 
Following the 1989 Loma Prieta Earthquake." Journal of Insurance Issues and Practices, March 1993, 16(1), pp. 1-14.

Bakshi, Gurdip S. and Chen, Zhiwu. "Inflation, Asset Prices, and the Term Structure of Interest Rates in Monetary Economies." Review of Financial Studies, Spring 1996, 9(1), pp. 241-75.

Barberis, Nicholas; Huang, Ming and Santos, Tano. "Prospect Theory and Asset Prices." Quarterly Journal of Economics, February 2001, 116(1), pp. 1-53.

Barberis, Nicholas, and Thaler, Richard. "A Survey of Behavioral Finance.” NBER Working Paper No. w9222, National Bureau of Economic Research, September 2002.

Barsky, Robert B. and DeLong, Bradford J. "Why Does the Stock Market Fluctuate?" Quarterly Journal of Economics, May 1993, 108(2), pp. 291-311.

Benartzi, Shlomo and Thaler, Richard H. "Myopic Loss Aversion and the Equity Premium Puzzle." Quarterly Journal of Economics, February 1995, 110(1), pp. 73-92.

Borgida, Eugene and Brekke, Nancy. "The Base Rate Fallacy in Attribution and Prediction," in John H. Harvey, W. Ickes, and R. Kidd, eds., New Directions in Attribution Research. Volume 3. Hillsdale, NJ: Erlbaum, 1981.

Borenstein, Severin and Zimmerman, Martin B. "Market Incentives for Safe Commercial Airline Operation." American Economic Review, December 1988, 78(5), pp. 913-35.

Bosch, Jean-Claude E.; Eckard, Woodrow and Singal, Vijay. "The Competitive Impact of Air Crashes: Stock Market Evidence." Journal of Law and Economics, October 1998, 41(2, Part 2), pp. 503-19.

Brennan, Michael J. and Xia, Yihong. "Stock Price Volatility and Equity Premium.” Journal of Monetary Economics, April 2001, 47(2), pp. 249-83.

Broder, Ivy E. "The Cost of Accidental Death: A Capital Market Approach." Journal of Risk and Uncertainty, March 1990, 3(1), pp. 51-63.

Bullard, James and Duffy, John. "Learning and Excess Volatility.” Macroeconomic Dynamics, April 2001, 5(2), pp. 272-302.

Camerer, Colin. "Individual Decision Making," in John H.
Kagel and Alvin E. Roth, eds., The Handbook of Experimental Economics. Chap. 8. Princeton: Princeton University Press, 1995, pp. 587-703.

Campbell, John Y. "Asset Pricing at the Millennium." Journal of Finance, August 2000, 55(4), pp. 1515-67.

Cagle, Julie A.B. "Natural Disasters, Insurer Stock Prices, and Market Discrimination: The Case of Hurricane Hugo." Journal of Insurance Issues, 1996, 19, pp. 53-68.

Clarida, Richard; Gali, Jordi and Gertler, Mark. "The Science of Monetary Policy: A New Keynesian Perspective." Journal of Economic Literature, December 1999, 37(4), pp. 1661-707.

Cochrane, John H. Asset Pricing. Princeton, NJ: Princeton University Press, January 2001.

DeLong, J. Bradford; Shleifer, Andrei; Summers, Lawrence H. and Waldmann, Richard J. "Noise Trader Risk in Financial Markets." Journal of Political Economy, August 1990a, 98(4), pp. 703-38.

DeLong, J. Bradford; Shleifer, Andrei; Summers, Lawrence H. and Waldmann, Richard J. "Positive Feedback Investment Strategies and Destabilizing Rational Speculation." Journal of Finance, June 1990b, 45(2), pp. 375-95.

DeLong, J. Bradford; Shleifer, Andrei; Summers, Lawrence H. and Waldmann, Richard J. "The Survival of Noise Traders in Financial Markets.” Journal of Business, January 1991, 64(1), pp. 1-19.

Economist. "Beyond the Business Cycle?” 23 October 1999

El-Gamal, Mahmoud A. and Grether, David M. "Are People Bayesian? Uncovering Behavioral Strategies.” Journal of the American Statistical Association, December 1995, 90(432), pp. 1137-45.

Evans, George and Ramey, Garey. "Expectations Calculation and Macroeconomic Dynamics." American Economic Review, March 1992, 82(1), pp. 207-24.

Fama, Eugene F. and Schwert, William G. "Asset Returns and Inflation." Journal of Financial Economics, November 1977, 5(2), pp. 115-46.

Folkes, Valerie S. "The Availability Heuristic and Perceived Risk." Journal of Consumer Research, June 1988, 15(1), pp. 13-23. 
Geske, Robert and Roll, Richard. "The Fiscal and Monetary Linkage between Stock Returns and Inflation." Journal of Finance, March 1983, 38(1), pp. 1-33.

Gordon, Myron J. "Dividends, Earnings, and Stock Prices." Review of Economics and Statistics, May 1959, 41(2, Part I), pp. 99-105.

Grether, David M. "Testing Bayes Rule and the Representativeness Heuristic: Some Experimental Evidence." Journal of Economic Behavior and Organization, January 1992, 17(1), pp. 31-57.

Grether, David M. "Bayes Rule as a Descriptive Model: The Representativeness Heuristic." Quarterly Journal of Economics, November 1980, 95(3), pp. 537-57.

Hirshleifer, David. "Investor Psychology and Asset Pricing." Journal of Finance, August 2001, 56(4), pp. 1533-97.

Kahneman, Daniel and Tversky, Amos. "On the Psychology of Prediction.” Psychological Review, 1973, 80, pp. 237-51.

Kahneman, Daniel; Slovic, Paul and Tversky, Amos, eds. Judgement Under Uncertainty: Heuristics and Biases. Cambridge: Cambridge University Press, 1982.

Kunreuther, Howard; Ginsberg, R.; Miller, L.; Sagi, P.; Borhan, B. and Katz, N., eds. Disaster Insurance Protection: Public Policy Lessons. New York: John Wiley Interscience, 1978.

Lamb, Reinhold P. "An Exposure-Based Analysis of PropertyLiability Insurer Stock Values Around Hurricane Andrew." Journal of Risk and Insurance, March 1995, 62(1), pp. 111-23.

Lang, Larry H.P. and Stulz, Rene M. "Contagion and Competitive Intra-industry Effects of Bankruptcy Announcements." Journal of Financial Economics, August 1992, 32(1) pp. 45-60.

Lehmann, Bruce N. "Asset Pricing and Intrinsic Values: Review Essay." Journal of Monetary Economics, December 1991, 28(3), pp. 485-500.

LeRoy, Stephen F. and Porter, Richard D. "The Present Value Relation: Tests Based on Implied Variance Bounds." Econometrica, May 1981, 49(3), pp. 555-74.

Lucas, Robert E. Jr. "Asset Prices in an Exchange Economy." Econometrica, November 1978, 46(6), pp. 1429-45.
Marshall, David A. "Inflation and Asset Returns in a Monetary Economy.” Journal of Finance, September 1992, 47(4), pp. 1315-42.

McDevitt, Catherine. "The Role of the Nominal Tax System in the Common Stock Returns/Expected Inflation Relationship." Journal of Monetary Economics, July 1989, 24(1), pp. 93-107.

Mitchell, Mark L. and Maloney, Michael T. "Crisis in the Cockpit? The Role of Market Forces in Promoting Air Travel Safety." Journal of Law and Economics, October 1989, 32(2, Part 1), pp. 329-55.

Mullainathan, Sendhil. "A Memory Based Model of Bounded Rationality.” Unpublished manuscript, MIT, April 1998.

Mullainathan, Sendhil. "A Memory-Based Model of Bounded Rationality.” Quarterly Journal of Economics, August 2002, 117(3), pp. 735-75.

Nelson, Charles R. "Inflation and Rates of Return on Common Stocks." Journal of Finance, May 1976, 31(2), pp. 471-83.

Nethercutt, Leonard L. and Pruitt, Stephen W. "Touched by Tragedy: Capital Market Lessons from the Crash of ValueJet Flight 592.” Economics Letters, November 1997, 56(3), pp. 351-58.

Perez-Quiros, Gabriel and Timmermann, Allan. "Firm Size and Cyclical Variation in Stock Returns." Journal of Finance, June 2000, 55(3), pp. 1229-62.

Rabin, Matthew. "Psychology and Economics." Journal of Economic Literature, March 1998, 36(1), pp. 11-46.

Rabin, Matthew. "A Perspective on Psychology and Economics.” European Economic Review, April 2002, 46(4-5), pp. 657-85.

Shelor, Roger M.; Anderson, Dwight C. and Cross, Mark L. "Gaining from Loss: Property-Liability Insurer Stock Values in the Aftermath of the 1989 California Earthquake." Journal of Risk and Insurance, September 1992, 59(3), pp. 476-88.

Sherman, Steven J. and Corty, Eric. "Cognitive Heuristics," in The Handbook of Social Cognition. Volume 3, Chap. 6. New York: Lawrence Earlbaum Associates, 1984, pp. 189-286. 
Shiller, Robert J. "Do Stock Prices Move Too Much To Be Justified by Subsequent Changes in Dividends?" American Economic Review, June 1981, 71(3), pp. 421-36.

Shiller, Robert J. Irrational Exuberance. Princeton, NJ: Princeton University Press, 2000.

Shiller, Robert J. "From Efficient Markets Theory to Behavioral Finance." Journal of Economic Perspectives, Winter 2003, 17(1), pp. 83-104.

Shleifer, Andrei and Vishny, Robert. "The Limits to Arbitrage." Journal of Finance, March 1997, 52(1), pp. 35-55.

Simon, Herbert A. "A Behavioral Model of Rational Choice." Quarterly Journal of Economics, February 1955, 69(1), pp. 99-118.

Timmermann, Allan. "Structural Breaks, Incomplete Information, and Stock Prices.” Journal of Business and Economic Statistics, July 2001, 19(3), pp. 299-314.
Tirole, Jean. "Asset Bubbles and Overlapping Generations." Econometrica, November 1985, 53(6), pp. 1499-528.

Tversky, Amos and Kahneman, Daniel. "Availability: A Heuristic for Judging Frequency and Probability." Cognitive Psychology, 1973, 5, pp. 207-32.

Tversky, Amos and Kahneman, Daniel. "Judgment under Uncertainty: Heuristics and Biases.” Science, 1974, 185, pp. 1124-31.

Weil, Philippe. "On the Possibility of Price Decreasing Bubbles.” Econometrica, November 1990, 58(6), pp. 1467-74.

Yamori, Nobuyoshi and Kobayashi, Takeshi. "Do Japanese Insurers Benefit from a Catastrophic Event? Market Reactions to the 1995 Hanshin-Awaji Earthquake." Journal of the Japanese and International Economies, March 2002, 16(1), pp. 92-108.

\section{Appendix}

\section{A MODEL}

Consider an event $\chi$ that agents are attempting to forecast with an associated indicator $X_{T}$ member of $\{0,1\}$, where $X_{T}=1$ if event $\chi$ occurs in period $T$. An agent's subjective probability, her estimate of the probability that $X_{T}=1$ conditional on the information set $\Omega_{T}$, is determined by a function $P: \Omega_{T} \rightarrow[0,1]$, which maps the information set into the probability space. The agent's information set consists of past realizations of $X_{T}$,

$$
\tilde{X}_{T-1}=\left\{X_{1}, X_{2}, \ldots, X_{T-1}\right\},
$$

as well as current informative and uninformative information,

$$
\begin{aligned}
& \tilde{Y}_{T}=\left\{Y_{1}, Y_{2}, \ldots, Y_{T}\right\}, \text { and } \\
& \tilde{Z}_{T}=\left\{Z_{1}, Z_{2}, \ldots, Z_{T}\right\},
\end{aligned}
$$

respectively. ${ }^{21}$ Suppose further that the event $\chi$ is serially uncorrelated and that information useful in forecasting $\chi$ in period $t$ is useful only for that period. ${ }^{22}$ That is, we assume that

\footnotetext{
${ }^{21}$ Here, information is uninformative if $\operatorname{Pr}\left[X_{T}=1 \mid Z_{T}\right]=\operatorname{Pr}\left[X_{T}=1\right]$.

22 These assumptions are employed for simplicity of exposition and are not necessary for the development of the model.
}

$$
\operatorname{Pr}\left[X_{T}=1 \mid \tilde{X}_{T-1}, \tilde{Y}_{T}\right]=\operatorname{Pr}\left[X_{T}=1 \mid Y_{T}\right] .
$$

The rational expectations solution can then be written

$$
P^{R}: Y_{T} \rightarrow[0,1],
$$

where the function $P^{R}$ follows Bayes's law (3). Thus, a rational agent with information $\Omega_{T}$ has subjective probability

$$
\operatorname{Pr}\left[X_{T}=1 \mid Y_{T}\right]=\frac{\operatorname{Pr}\left[Y_{T} \mid X_{T}=1\right] \operatorname{Pr}\left[X_{T}=1\right]}{\operatorname{Pr}\left[Y_{T}\right]} .
$$

Now consider a model in which the agent employs the heuristics outlined in the previous sections. We follow Mullainathan (2002) in assuming that the memory processes of agents is incomplete, i.e., that agents forget some realizations of $X_{T}$. That is, the agent's recalled information set, $\hat{\Omega}_{T}$, can be written as

$$
\hat{\Omega}_{T}=\left\{\hat{X}_{T}, Y_{T}, Z_{T}\right\},
$$

where

$$
\hat{X}_{T}=\left\{X_{1, T}^{\ddagger}, X_{2, T}^{\ddagger}, \ldots, X_{T-1, T}^{\ddagger}\right\}
$$

and 


$$
X_{t, T}^{\ddagger}=\left\{\begin{array}{ll}
X_{t} & \text { with probability } p_{t \mid T} \\
0 & \text { with probability } 1-p_{t, T}
\end{array} .\right.
$$

Essentially, $X_{t, T}^{\ddagger}$ is a combination of two indicators: whether the event occurs in time $t$ and whether time $t$ is remembered in time $T$. The likelihood that an event that occurred in period $t$ is recalled in period $T$ is a function of the time since its last recall, associated events in time $t$ (that is, $Y_{t}$ and $Z_{t}$ ), and the current environment, $Y_{T}$ and $Z_{T}$. Define $\alpha_{t, T}=$ $\alpha\left(Y_{t}, Z_{t}, Y_{T}, Z_{T}\right)$, where the function $\alpha(\cdot)$ measures the distance between the points $\left(Y_{t}, Z_{t}\right)$ and $\left(Y_{T}, Z_{T}\right)$ in Cartesian space. We can then write the likelihood of recalling the event of time $t$ at a later time $T$ as

$$
p_{t, T}=F\left(X_{t, T-1}^{\ddagger}, \alpha_{t, T}\right),
$$

where the function $F(\because$,$) has the following properties:$ $F_{1}(\because)>0$ and $F_{2}(\because)<$,0 . The former indicates that periods recalled in period $T-1$ are more likely to be recalled in $T$. The latter stipulation indicates that it is more likely that $t$ will be recalled the closer that the current environment is to elements temporally associated with period $t$.

In this framework, the agent forms an estimate of the likelihood of $\chi$ in time $T$ based, in part, on how closely $T$ resembles any time $t<T$ in which $\chi$ occurred through the closeness function $\alpha(\cdot)$.

Limited memory makes the probability judgments noisy and biased toward salient events that may or may not be informative. Elements of the agent's information set are a subset of the total information available. Thus, the agent's update has the property that forgetting the occurrence of an event in the past will decrease the subjective probability estimate.

Additionally, salience increases the perceived probability, since salience increases the likelihood of recall. Moreover, since the information set varies over time, the volatility of the estimated probability is greater than the volatility of a learned probability with perfect recall (e.g., OLS learning). In the perfect recall case, information gathered over time reduces the volatility. In the limited-memory case, information that is forgotten biases the subjective probability down, while recalled probability biases it up, each period inducing higher volatility.

Agents make errors in neglecting base rates and consequently bias subjective probabilities upward when they perceive that new information is relevant. It can be shown that, regardless of the direction new information should move the posterior probability, agents employing an updating function that neglects base rates necessarily overestimate the value of the new information. Agents' subjective probabilities are biased toward their anchor.

\section{A Formal Financial Application}

This appendix develops a formal application of the heuristic probability judgments in an asset pricing model. We will initially follow Lucas (1978) to develop a simple general equilibrium framework to study the effects of subjective probabilities.

There are two assets: a risk-free, discount bond with a price $B_{t}$ and interest rate $r_{t}^{f}=\frac{1}{B_{t}}-1$; and a stock with price $S_{t}$. The stock pays out an infinite stream of perishable, real dividends, $\left\{D_{s}\right\}_{s=t}^{\infty}$, whose growth rates, $d_{t} \equiv \frac{D_{t}}{D_{t-1}}-1$, follow a Bernoulli process:

$$
d_{t}=\left\{\begin{array}{l}
d_{h} \text { with probability } \pi_{D} \\
d_{t} \text { with probability } 1-\pi_{D}
\end{array} \quad 0 \leq \pi_{D} \leq 1.23\right.
$$

Agents' information set consists of a finite sample space, $\Omega_{T}$, comprising all sequences of the form

$$
\begin{aligned}
\omega_{T}=\{ & \left\{X_{\left\{d_{1}=d_{h}\right\}}, X_{\left\{d_{2}=d_{h}\right\}}, \ldots, X_{\left\{d_{T}=d_{h}\right\}},\right. \\
& \left.X_{\left\{z_{1}=z_{h}\right\}}, X_{\left\{z_{2}=z_{h}\right\}}, \ldots, X_{\left\{z_{T}=z_{h}\right\}}\right\},
\end{aligned}
$$

where $X_{\{\cdot\}}$ denotes a standard indicator function. Each $\omega_{T}$ provides a record of possible sequences of dividend growth rates and realizations of an uninformative variable $Z_{t}$. In our previous notation, $\Omega_{T}=\left\{\tilde{X}_{T}, \tilde{Z}_{T}\right\}$. For simplicity, the only informative variable is dividends. Also, assume that the uninformative variable $Z_{t}$ follows another binomial distribution independent of dividends, i.e., the rate of change of $Z_{t}, Z_{t} \equiv \frac{Z_{t}}{Z_{t-1}}-1$, follows a Bernoulli process:

$$
Z_{t}=\left\{\begin{array}{l}
Z_{h} \text { with probability } \pi_{Z} \\
Z_{l} \text { with probability } 1-\pi_{Z}
\end{array} \quad 0 \leq \pi_{Z} \leq 1 .\right.
$$

Therefore, the joint probability measure of each realization $\omega_{T}$ is given by

$$
\begin{aligned}
P\left(\omega_{T}\right)= & {\left[\pi_{D}^{j}\left(1-\pi_{D}\right)^{T-j}\right] \cdot\left[\pi_{Z}^{i}\left(1-\pi_{Z}\right)^{T-i}\right] } \\
& 0 \leq j \leq T \quad 0 \leq i \leq T,
\end{aligned}
$$

where $\omega_{T}$ is any state characterized by both $j$ occur-

\footnotetext{
${ }^{23}$ Without loss of generality, assume that $d_{h}>d_{1}>-1$, so that dividends are nonnegative provided $D_{0}>0$.
} 
rences of high dividend growth and $i$ occurrences of a high rate of growth of $Z$. While the marginal probability for dividends is

$$
P\left(\left\{X_{\left\{d_{1}=d_{h}\right\}}, X_{\left\{d_{2}=d_{h}\right\}}, \ldots, X_{\left\{d_{T}=d_{h}\right\}}\right\}\right)=\left[\pi_{D}^{j}\left(1-\pi_{D}\right)^{T-j}\right],
$$

since $D$ and $Z$ are independent.

From basic asset pricing principles, in the absence of risk aversion, we can find the price of both assets as the present discounted value of the future stream of cash flows generated by each of them:

$$
\begin{gathered}
S_{t}=E_{t}\left[\beta\left(S_{t+1}+D_{t+1}\right)\right] \\
B_{t}=E_{t}[\beta]=\beta,
\end{gathered}
$$

where $\beta=\frac{1}{1+\rho}, \rho>0$ is the subjective rate of impatience and $E_{t}[\cdot]$ denotes the conditional expectation operator measurable with respect to available information. Under the assumption of risk neutrality, this simple asset pricing model is a specialization of a classical present-discounted value dividend model (see Lehmann, 1991) to the binomial distribution case.

In the full-information case where the parameters $\left(\pi_{D}, d_{h}, d_{l}, \pi_{z}, z_{h}, Z_{l}\right)$ of the joint process for $D$ and $Z$ are known to the agent, a solution for asset prices can be obtained easily using the method of undetermined coefficients. Since the lattices for $D$ and $Z$ are independent, $Z$ does fail to convey any useful information concerning $D$ and an agent will rationally base her portfolio and pricing decisions on the marginal probability measure for $D$ only, a standard (transformation of a) binomial distribution parameterized by $\left\{\pi_{D}, d_{h}, d_{l}\right\}$. It is then possible to demonstrate that

$$
S_{t}^{F I}=\lim _{T \rightarrow \infty} E_{t}\left[\sum_{j=1}^{T}\left(\beta^{j} \prod_{i=1}^{j} D_{t+i} / D_{t+i-1}\right)\right] \cdot D_{t} .
$$

This solution for the equilibrium stock price under full information shows that the stock price is a simple, constant multiple of dividends. $\Psi^{F I}$ denotes the constant pricing kernel or, equivalently, the pricedividend ratio. The explicit solution to (10) can then be derived as

$$
S_{t}^{F I}=\Psi^{F I} D_{t}=\frac{1+d_{l}+\pi\left(d_{h}-d_{l}\right)}{\rho-d_{l}-\pi\left(d_{h}-d_{l}\right)} D_{t}=\frac{1+E\left[d_{t}\right]}{\rho-E\left[d_{t}\right]} D_{t},
$$

while the full-information bond price, $B_{t}^{F I}$, is

$$
B^{F I}=\frac{1}{1+\rho}>0 .
$$

Equivalently, the time-invariant equilibrium riskfree rate, $r^{F I}$, is simply $\rho>0$. Since $r^{F I}=\rho$, it is straightforward to rewrite (11) as

$$
S_{t}^{F I}=\frac{1+E\left[d_{t}\right]}{r^{F I}-E\left[d_{t}\right]} D_{t},
$$

which shows the exact equivalence between the solution under full-information rational expectations and the classic Gordon's (1959) formula, popular in applied corporate finance.

\section{The Heuristics-Based Solution}

Suppose that $\pi_{D}$ is unknown and must be subjectively calculated in a recursive fashion. A subjective assessment of $\pi_{D}$ at time $t$ is equivalent to calculating a probability function $\hat{P}^{S}\left(\hat{\Omega}_{t}\right) \equiv$ $\operatorname{Pr}\left[X_{t+k}=1 \mid \hat{\Omega}_{t}\right]$ for all $\mathrm{k} \geq 1$, where $\hat{\Omega}_{t}$ is as defined in (4). The agent believes that the value of the stock depends not only on future dividend payments, i.e.,

$$
\hat{P}^{S}\left(\hat{\Omega}_{t}\right) \equiv \operatorname{Pr}\left[X_{t+k}=1 \mid \hat{X}_{t} ; \tilde{Z}_{t}\right] \text { for all } k \geq 1,
$$

but also on irrelevant information she uses. Assume that the agent's information set is $\hat{\Omega}_{t}=\left\{\hat{X}_{t}, \tilde{Z}_{t}\right\}$, where

$$
\begin{gathered}
\hat{X}_{t} \equiv\left\{X_{j, t}^{*}\right\}_{j=1}^{t} \\
X_{j, t}^{*}= \begin{cases}X_{t} & \text { with probability } \quad p_{j, t} \\
0 & \text { with probability } 1-p_{j, t}\end{cases}
\end{gathered}
$$

and

$p_{j, t}=\theta^{t-j} \alpha\left(Z_{j}, Z_{t}\right)$ with $\frac{d \alpha\left(Z_{j}-Z_{t}\right)}{d\left(Z_{j}-Z_{t}\right)}<0$, and $\theta<1$.

The parameter $\theta$ is an additional, subjective discount factor applied to information flows: Since $\theta<1$, the further back in time an observation on the dividend growth rate is, the more unlikely it is that it will belong to the recalled information set $\hat{\Omega}_{t} . \alpha\left(Z_{j}-Z_{t}\right)$ might be simply taken to be the inverse of the Euclidean distance between $Z_{j}$ and $Z_{t}{ }^{24}$ :

$$
\alpha\left(Z_{j}-Z_{t}\right) \equiv \frac{1}{1+\sqrt{\left(Z_{j}-Z_{t}\right)^{2}}} .
$$

\footnotetext{
24 In the presence of a drifting process for $Z$, it would be advisable to de-mean $Z_{t}$ by subtracting $\delta_{t}$ and de-mean $Z_{j}$ by subtracting $\delta_{j}$, where $\delta$ is the drift.
} 
The current observation on the dividend growth rate belongs to $\hat{\Omega}_{t}$ since $\alpha\left(Z_{j}-Z_{t}\right)=\theta^{0}=1$. Also, the probability that $X_{j, t}$ is a member of $\hat{\Omega}_{t}$ is a function not only of the growth rate of $Z$ but its level as well.

Under our binomial assumptions, maximumlikelihood delivers the following (recalled) sample proportion estimator:

$$
\hat{P}^{S}\left(\hat{\Omega}_{t}\right)=\hat{\pi}_{D}^{S}\left(\hat{\Omega}_{t}\right)=\frac{\sum_{j=1}^{t} X_{j, t}^{*}}{\sum_{j=1}^{t} I_{\left\{x_{j, t}^{*}=x_{j, t}\right\}}},
$$

where $I_{\left\{x_{j, t}^{*}=x_{j, t}\right\}}$ is another indicator variable that takes a value of 1 when $X_{j, t}$ is a member of $\hat{\Omega}_{t}$ (it was recalled) and zero otherwise.

It is now straightforward to calculate the incomplete information, equilibrium asset prices in the presence of heuristic biases. When $\rho>\hat{\pi}_{D}^{S}\left(\hat{\Omega}_{t}\right) d_{h}+$ $\left(1-\hat{\pi}_{D}^{S}\left(\hat{\Omega}_{t}\right)\right) d_{l}$, the heuristic-based stock price, $S_{t}^{H}$, is given by

$$
\begin{aligned}
S_{t}^{H}(\theta, \gamma, \alpha(\cdot)) & =\Psi^{H}\left(\hat{\Omega}_{t} ; \theta, \gamma, \alpha(\cdot)\right) D_{t} \\
& =\frac{1+d_{l}+\hat{\pi}_{D}^{S}\left(\hat{\Omega}_{t}\right)\left(d_{h}-d_{l}\right)}{\rho-d_{l}-\hat{\pi}_{D}^{S}\left(\hat{\Omega}_{t}\right)\left(d_{h}-d_{l}\right)} D_{t} \\
& =\frac{1+\hat{E}_{t}^{S}\left[d_{t+1}\right]}{r^{H}-\hat{E}_{t}^{S}\left[d_{t+1}\right]} D_{t},
\end{aligned}
$$

while the full-information bond price, $B_{t}^{H}$, is $r^{H}=$ $\rho>0 .{ }^{25}$ Equation (13) differs from the full-information result as the equilibrium stock price stops being a fixed multiple of dividends; on the contrary, $\Psi_{t}^{H}$ is time-varying, fitting the empirical observations that price-dividend ratios are subject to long swings. The variation in the price-dividend ratio derives from changes in the memory-based conditional expectation, $\hat{E}_{t}^{S}\left[d_{t+1}\right]$. More generally, observe that even in the absence of strong changes in dividends, (12) itself implies that $\Psi_{t}^{H}$ ought to display considerable variability.

\section{Excess Volatility of Stock Prices}

From (10) it follows that 26

$$
\begin{aligned}
1+r_{t}^{F I} \equiv & \frac{S_{t}^{F I}+D_{t}}{S_{t-1}^{F I}}=\frac{\Psi^{F I} D_{t}+D_{t}}{\Psi^{F I} D_{t-1}}= \\
& \Psi^{F I} d_{t}+\frac{1}{\Psi^{F I}} d_{t}=\left(\Psi^{F I}+\frac{1}{\Psi^{F I}}\right) d_{t} \simeq \Psi^{F I} d_{t},
\end{aligned}
$$

so that the volatility of gross stock returns, $1+r_{t}^{F I}$, is a constant factor $\sqrt{\Psi^{F I}}$ times the volatility of the rate of growth of fundamentals. Since empirical research has shown stock returns to be over ten times more volatile than fundamentals, this reveals an inconsistency, as $\sqrt{\Psi^{F I}}>10$ implies $\Psi^{F I}>100$, too high a price-dividend ratio.

To the contrary, (13) shows that the excess stock volatility puzzle disappears when the price-dividend ratio, $\Psi$, that maps dividends into equilibrium stock prices is time-varying, as a result of limited recall capabilities. In this case

$$
1+r_{t}^{H}=\left(\Psi_{t}^{H}+\frac{1}{\Psi_{t}^{H}}\right) d_{t} \simeq \Psi_{t}^{H} d_{t}
$$

so that

$$
\operatorname{Var}\left[1+r_{t}^{H}\right]=\operatorname{Var}\left[\Psi_{t}^{H}\right]+\operatorname{Var}\left[d_{t}\right]+2 \operatorname{Cov}\left[\Psi_{t}^{H}, d_{t}\right] .
$$

When $\operatorname{Cov}\left[\Psi_{t}^{H}, d_{t}\right]>0$, an increase of the volatility of stock returns (as a result of heuristic biases) will obtain in a full-information framework. Such a case is highly likely under the heuristic rules of our framework.

\footnotetext{
25 The notation stresses that heuristic-based stock prices do depend on the strength and structure of the assumed biases, as represented by the parameters $\theta, \gamma$, and the functional form of $\alpha(\cdot) . \hat{E}_{t}^{S}[\cdot]$ is an expectation taken with respect to the subjective probability assessment of the agent.
}

\footnotetext{
26 The approximation is justified by realistic values of the price-dividend ratio in excess of 20 to 30 .
} 
RE V I E W 